\title{
Traumatic and Non-Traumatic Spinal Cord-Injured Patients in Quebec, Canada: 1. Epidemiological, Clinical and Functional Characteristics
}

\author{
Pascal Rouleau, ${ }^{1,4}$, Edouard Ayoub ${ }^{2}$ and Pierre A. Guertin ${ }^{*}, 1,2,3,4$ \\ ${ }^{1}$ Centre Hospitalier Universitaire de Quebec, Neuroscience Unit, Quebec City, Quebec, Canada \\ ${ }^{2}$ Universite Laval, Faculty of Medicine, Department of Psychiatry and Neuroscience, Quebec City, Quebec, Canada \\ ${ }^{3}$ Nordic Life Science Pipeline, Quebec City, Canada \\ ${ }^{4}$ Neurospina Therapeutics, Quebec City, Canada
}

\begin{abstract}
Objective: Differences between traumatic (TSCI) and non-traumatic (NTSCI) spinal cord-injured patients with comparable geographical and socio-economical background have rarely been studied. The objective was to examine and compare a set of epidemiological, clinical, and functional characteristics in TSCI and NTSCI patients.

Methods: This is a community-based, cross-sectional study of medical records from a cohort of one hundred and seventyfive (175) chronic spinal cord-injured patients (94 TSCI and 81 NTSCI individuals) who were treated at the Interval Rehabilitation Center located in Trois-Rivieres, Province of Quebec, Canada.

Results: Clear differences in age, gender, extent and level of injury or associated conditions (also called secondary complications) were found between TSCI and NTSCI patients. Only one (1/81) completely injured patients was identified among the NTSCI group whereas completely injured patients constituted $37.8 \%$ of all TSCI patients. The percentage of patients with associated conditions including neurogenic bladder, neurogenic bowel, urinary tract infection, and pressure ulcer problems was significantly greater in TSCI than NTSCI patients. In contrast, a comparable proportion of TSCI and NTSCI patients was experiencing neuropathic pain.

Conclusions: Given these differences between groups as well as regional-specific differences reported in studies from some other countries, it may be suggested that therapeutic approaches developed to treat these health problems and socalled associated conditions could be targeted for specific groups and subgroups of spinal cord-injured patients.
\end{abstract}

Keywords: Spinal cord injury, spinal disease, incidence, prevalence, functional, clinical.

\section{INTRODUCTION}

Spinal cord injury (SCI) typically induces devastating damages leading to a permanent loss of sensory and voluntary motor functions. In recent years, associated conditions or so-called secondary complications have received increasing attention from clinicians and scientists. It is now generally recognized that many SCI patients will develop important and often life-threatening complications several months to several years post-trauma. For instance, muscle wasting, osteoporosis, cardiovascular problems, immune deficiencies, hormonal imbalance, skin ulcers, anemia and urinary tract infections are among the problems typically encountered by chronic TSCI individuals (see also related papers)[1-4]. However, the extent to which these complications and related characteristics are similarly found in TSCI and NTSCI patients remains incompletely understood. This said, some studies have reported evidence suggesting that clinical, functional and epidemiological differences may exist between TSCI and NTSCI patients. For instance, higher risks of TSCI were found during

*Address correspondence to this author at the Laval University Medical Center (CHUL), Neuroscience Unit, RC-9800, 2705 Laurier Boulevard, Quebec City, Quebec, Canada; G1V 4G2; Tel: (418) 656-4141 ext. 48831; Fax: (418)654-2753; E-mail: Pierre.Guertin@crchul.ulaval.ca adolescence and early adulthood males and females with a male to female ratio of $4: 1$. In contrast, higher risks of NTSCI were reported in older adults with a more or less even male to female ratio $[5,6]$. Given that several SCIrelated characteristics are increasingly believed to depend upon social-related factors [7-9], it may be critical for proper comparisons between TSCI and NTSCI people to study these characteristics in a rather homogenous and thus comparable (e.g., geographically, socio-politically, and culturally) cohort of patients. Consequently, the main aim of this study was to assess and compare in the relatively homogenous community of Trois-Rivieres City, clinical, functional, and epidemiological characteristics of TSCI and NTSCI patients. This article is the first of a series of three papers aimed to describe also biochemical and pharmacological characteristics associated with TSCI and NTSCI patients [10, $11]$.

\section{METHODS}

\section{Study Population}

An access to all medical records of SCI patients was provided by the Interval Rehabilitation Center $(n=185)$. However, this investigation excluded the medical records that did not contain basic information on the patient such as the cause of injury, the time since injury or the extent and 
level of injury $(\mathrm{n}=10)$. Consequently, data from 175 medical records of male and female patients that have been SCI traumatically (94 patients) or non-traumatically (81 patients) for at least 1 year and typically less than 10 years were used in this study. Most TSCI patients but only 1 NTSCI patient were functionally classified using the standard American Spinal Cord Association (ASIA) classification (http://www.asia-spinalinjury.org/publications/2006_Classif _worksheet.pdf). Trois-Rivieres is a community constituted of 129,000 people (2010 statistics - www.stat.gouv.qc.ca) that is generally considered as having a relatively old population composed of a large proportion of welfare bluecollar workers (i.e., in 1998, it was identified as one of the poorest cities in the Province of Quebec). The education level is also among the lowest of the Province with less than $13 \%$ of the population with a university diploma. The city is known for its lack of socio-cultural diversity and immigration (it is composed essentially of white people less than $4 \%$ of the city's population belongs to visible minorities)(www.theglobeand mail.com). This protocol was approved by the institution (Interval Rehabilitation Center, Trois-Rivieres, Quebec, Canada) as well as by an independent ethics committee (International Review Board Services, Aurora, ON, Canada).

\section{Study Outcomes and Data Extraction Form}

The medical records were thoroughly examined in order to find data corresponding with the following categories which composed our Data Extraction Form. The outcome measures of the Data Extraction Form included the type of injury (traumatic or non-traumatic), cause, gender, level of injury, extent of injury (either complete or incomplete), time since injury, age at injury, and all reported 'associated conditions' that were found in the medical records.

\section{Statistical Analysis}

Clinical, functional and epidemiological data presented in this study were expressed as arithmetic sums (incidences), percentages, medians or means \pm standard deviations. Statistical analysis consisted in comparing means by Student's $T$ tests and percentages by Pearson's chi-square tests (Prism V5, Graph Pad Software, LaJolla, CA, USA). The threshold of probability was $\mathrm{p}=0.05$.

\section{Results}

The results showed that the most frequent type of trauma was induced by motor vehicle accidents (52.5\%). Specifically, $36.7 \%, 8.4 \%$, and $7.4 \%$ of all TSCI accidents were attributed to cars, motorcycles or recreational vehicles (e.g., ATVs, snowmobiles), respectively Fig. (1). The other main types of trauma included falls $(15.8 \%)$ and injuries at work (11.6\% professional- or industrial-related). Among other causes, it is worth noticing that accidents associated with fire arms constituted only $3.1 \%$ of all TSCI patients . It goes without saying that the etiology of NTSCI vs. TSCI is profoundly different. In this study, the results showed that the main cause of NTSCI was myelopathy associated with stenosis $(34.5 \%)$ or with viral infection/inflammation whereas syringomelia $(9.9 \%)$, myeloma $(9.9 \%)$ and hernia (9.9\%) constituted the other main cases of NTSCI found in Trois-Rivieres Fig. (2).

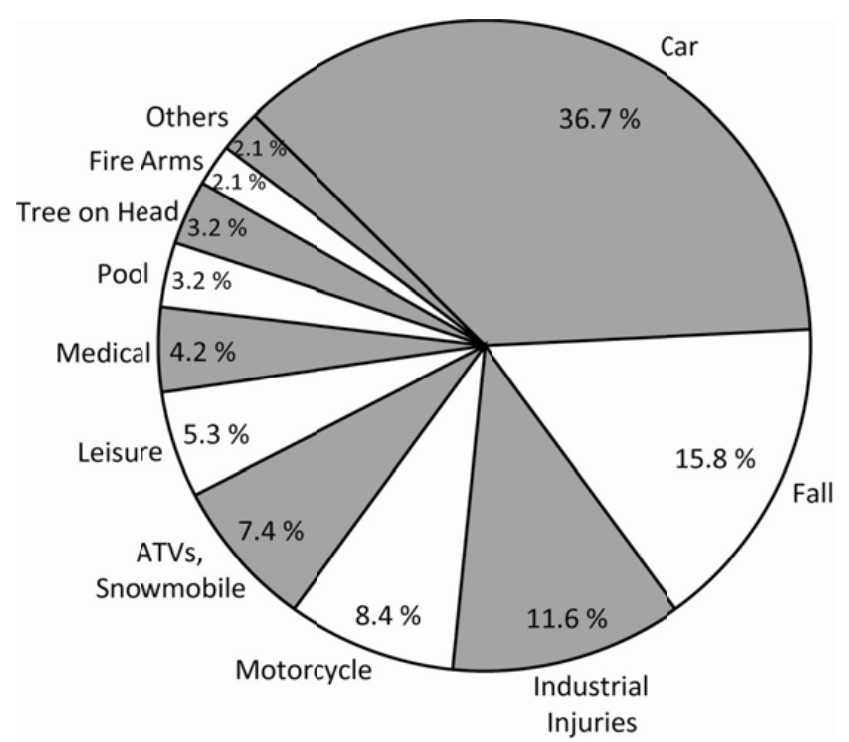

Fig: (1). Causes of traumatic spinal cord injury.

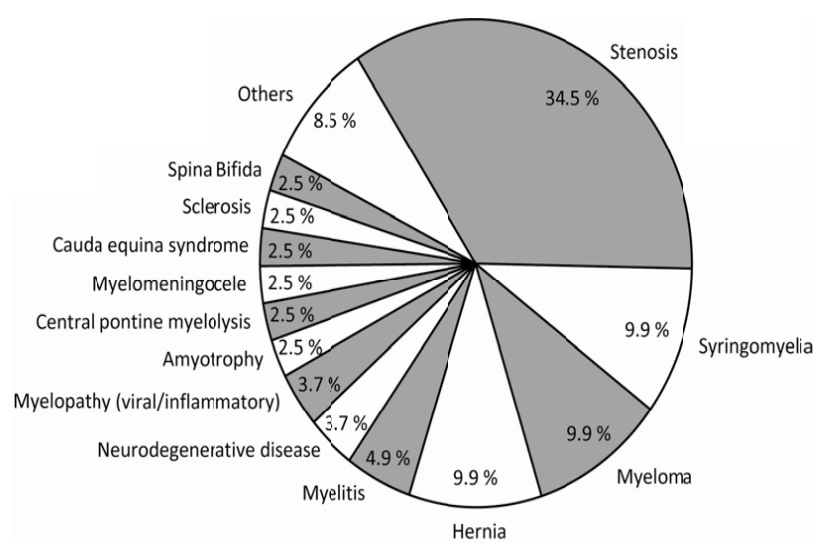

Fig. (2). Causes of non-traumatic spinal cord injury.

As reported also elsewhere [5,6], clear differences in age and sex between TSCI and NTSCI patients was also found in this study. For instance, on average, TSCI patients (males and females) were $36.8 \pm 17.8$ year-old (the median was 40.5 year-old) at the time of injury (Table 1). Significantly ( $\mathrm{P}=$ 0.001 ) older people at the time of injury (i.e., when diagnosed clinically) constituted the NTSCI group (48.8 \pm 22.2 year-old) (the median was 41.5 year-old). A clearly greater proportion of males versus females were TSCI $(74.5 \%$ vs. $25.5 \%)$ which, again, is in clear contrast with the results from NTSCI patients $(53.1 \%$ were men and $46.9 \%$ were women, Table 1). However, within each group, the age at injury was comparable $(\mathrm{P}>0.05)$ between men and women (Table 2 , TSCI men $38.6 \pm 17.3$ vs. TSCI women $31.7 \pm 18.6$ and NTSCI men $49.6 \pm 22.1$ vs. NTSCI women $49.3 \pm 23.3)$. In the group of TSCI patients, most males were young adults between 10 and 29 years of age which constituted $47.9 \%$ of all cases (Table $\mathbf{3}$ ). In turn, the age at injury of NTSCI patients was more evenly distributed (from birth to 89 year-old) with a small peak ( $21.0 \%$ of all cases) between 50-59 year-old (Table $\mathbf{3}$ ). 
Table 1. Age, Gender, Type and Completeness of Spinal Cord Injury

\begin{tabular}{|c|c|c|c|}
\hline & TSCI $(n=94)$ & $\operatorname{NTSCI}(n=81)$ & $X^{2}$ and significance \\
\hline Age at injury & $36.8 \pm 17.8$ & $48.8 \pm 22.2$ & $\mathrm{P}=0.001$ \\
\hline Age at 31 dec. 2008 & $45.0 \pm 16.9$ & $59.4 \pm 17.9$ & $\mathrm{P}<0.001$ \\
\hline Time since injury & $8.2 \pm 8.3$ & $9.7 \pm 11.3$ & $\mathrm{P}>0.05$ \\
\hline Male & $74.5(70)$ & $53.1(43)$ & $X^{2}=8.695$ \\
\hline Female & $25.5(24)$ & $46.9(38)$ & $\mathrm{P}=0.003$ \\
\hline Types of injury & $\%(\mathrm{n}=90)$ & $\%(\mathrm{n}=80)$ & \\
\hline Paraplegic incomplete & $35.6(32)$ & $52.5(42)$ & $X^{2}=34.84$ \\
\hline Level of injury & $\%(n=93)$ & $\%(\mathrm{n}=80)$ & \\
\hline Cervical & $40.8(38)$ & $36.4(29)$ & $X^{2}=20.58$ \\
\hline Cervical and thoracic & $2.2(2)$ & $3.8(3)$ & $\mathrm{P}=0.005$ \\
\hline Thoracic & $33.3(31)$ & $23.7(19)$ & \\
\hline Thoracic and lumbar & $5.4(5)$ & $2.5(2)$ & \\
\hline Lumbar & $18.3(17)$ & $15.0(12)$ & \\
\hline Lumbar and sacral & $0(0)$ & $6.3(5)$ & \\
\hline Degenerative diseases & $0(0)$ & $10.0(8)$ & \\
\hline
\end{tabular}

Table 2. Age at Injury and Other Differences Between TSCI and NTSCI

\begin{tabular}{|l|c|c|c|}
\hline & Male & Female & $(\mathrm{n}=24)$ \\
\hline \hline TSCI & $(\mathrm{n}=70)$ & $31.7 \pm 18.6$ & $P>0.05$ \\
\hline Age at injury & $38.6 \pm 17.3$ & $44.0 \pm 17.3$ & $P>0.05$ \\
\hline Age at 31 dec. 2008 & $45.4 \pm 16.9$ & $12.3 \pm 10.9$ & $P=0.002$ \\
\hline Time since injury & $6.8 \pm 6.8$ & $(\mathrm{n}=38)$ & $P>0.05$ \\
\hline NTSCI & $49.6 \pm 22.1$ & $59.3 \pm 23.3$ & $P>0.05$ \\
\hline Age at injury & $52.2 \pm 19.3$ & $58.3 \pm 21.5$ & $P>0.05$ \\
\hline Age at injury excluding diseases at birth & $59.9 \pm 16.4$ & $9.8 \pm 10.5$ & $P>0.05$ \\
\hline Age at 31 dec. 2008 & $9.6 \pm 12.1$ & \\
\hline Time since injury & $(\mathrm{n}=43)$ & \\
\hline
\end{tabular}

The extent of injury was also statistically $(\mathrm{P}<0.05)$ different between TSCI and NTSCI patients. The proportion of patients with incomplete paraplegia, complete paraplegia, incomplete tetraplegia, and complete tetraplegia was rather evenly distributed in the TSCI group (35.6\%, 22.2\%, 26.7\% and $15.5 \%$, respectively) whereas essentially no (1\% or $1 / 81$ patient) completely injured (with paraplegia or tetraplegia) patients were found in the NTSCI group (Table 1). Data presented for male vs. female TSCI and NTSCI patients unexpectedly revealed a different gender-related trend. Indeed, for men, there was almost a $2: 1$ ratio $(62 \%$ vs. $38 \%)$ of paraplegia vs. tetraplegia whereas, for women, an inverse ratio $(42 \%$ vs. $58 \%)$ of paraplegia vs. tetraplegia was found (Table 4). However, there was a comparable trend when comparing complete vs. incomplete patients within each group of men or women with $39 \%$ vs. $61 \%$ of complete and 
Table 3. Distribution of Age at Injury Between Male and Female TSCI and NTSCI

\begin{tabular}{|c|c|c|c|c|c|}
\hline \multirow{2}{*}{ TSCI; age at injury } & Male & Female & Total & Complete & Incomplete \\
\hline & $\%(n=70)$ & $\%(n=24)$ & $\%(n=94)$ & $\%(n=34)$ & $\%(n=54)$ \\
\hline $0-9$ & $1.4(1)$ & $0(0)$ & $1.1(1)$ & $0(0)$ & $1.9(1)$ \\
\hline $10-19$ & $14.3(10)$ & $29.2(7)$ & $18.1(17)$ & $17.6(6)$ & $14.8(8)$ \\
\hline $20-29$ & $28.6(20)$ & $33.3(8)$ & $29.8(28)$ & $38.2(13)$ & $27.8(15)$ \\
\hline $30-39$ & $10.0(7)$ & $12.5(3)$ & $10.6(10)$ & $11.8(4)$ & $9.3(5)$ \\
\hline $40-49$ & $11.4(8)$ & $12.5(3)$ & $11.7(11)$ & $5.9(2)$ & $14.8(8)$ \\
\hline $50-59$ & $21.4(15)$ & $0(0)$ & $15.9(15)$ & $23.5(8)$ & $12.9(7)$ \\
\hline $60-69$ & $10.0(7)$ & $4.2(1)$ & $8.5(8)$ & $3.0(1)$ & $12.9(7)$ \\
\hline $70-79$ & $2.9(2)$ & $8.3(2)$ & $4.3(4)$ & $0(0)$ & $5.6(3)$ \\
\hline $0-9$ & $7.5(3)$ & $5.6(2)$ & $6.6(5)$ & \multicolumn{2}{|c|}{ TSCI male / female } \\
\hline $10-19$ & $7.5(3)$ & $5.6(2)$ & $6.6(5)$ & \multicolumn{2}{|c|}{$X^{2}=9.907$} \\
\hline $20-29$ & $5.0(2)$ & $11.1(4)$ & $7.9(6)$ & \multicolumn{2}{|c|}{$P=0.194$} \\
\hline $30-39$ & $5.0(2)$ & $8.3(3)$ & $6.6(5)$ & \multicolumn{2}{|c|}{ NTSCI male / female } \\
\hline $40-49$ & $15.0(6)$ & $19.4(7)$ & $17.1(13)$ & \multicolumn{2}{|c|}{$X^{2}=2.724$} \\
\hline $50-59$ & $22.5(9)$ & $19.4(7)$ & $21.0(16)$ & \multicolumn{2}{|c|}{$P=0.951$} \\
\hline $60-69$ & $20.0(8)$ & $11.1(4)$ & $15.8(12)$ & \multicolumn{2}{|c|}{ TSCI complete / incomplete } \\
\hline
\end{tabular}

incomplete TSCI male patients and $32 \%$ vs. $68 \%$ of complete and incomplete TSCI female patients (Table 4). Corresponding numbers were found when examining more closely the specific level of injury (i.e., cervical, thoracic, lumbar, sacral). Most patients in both groups were either cervically (TSCI $43 \%$ and NTSCI $40.2 \%$ ) or thoracically (TSCI 38.7\% and NTSCI 26.2\%) injured. Only a few TSCI patients were injured at the lumbar or sacral level $(18.3 \%)$ whereas $21.3 \%$ of NTSCI patients were injured at the lower levels (i.e., excluding typically widespread neurodegenerative diseases, Table 1).

One of the most interesting findings in this study was the clear difference found in incidence of associated conditions or so-called secondary complications. A rather large proportion of TSCI patients suffered of problems such as neurogenic bladder (52.2\%), neurogenic bowel (51.1\%), spasticity $(48.9 \%)$, pressure ulcers (41.3) and urinary tract infections $(26.1 \%)$ whereas a much lower proportion of NTSCI patients in Trois-Rivieres City suffered of these conditions $\quad(11.1 \%, \quad 8.3 \%, \quad 29.2 \%, \quad 18.1 \%, \quad 2.8 \%$, respectively). This said, there was one condition, chronic pain, for which TSCI and NTSCI patients were both largely affected $(65.2 \%$ and $66.7 \%$, respectively, Table 5). It is important to specify that some of these associated conditions were possibly affected or even due to circumstances related directly with the accident in the case of TSCI. For instance, acute pain from nerve damage during a car accident may possibly lead to chronic pain that is not entirely associated with chronic SCI per se but, instead, with the circumstances of the car accident (e.g., the security belt crushing a peripheral nerve at the shoulder level occurring simultaneously with a SCI at the cervical level caused by airbag deployment).

\section{DISCUSSION}

This study reveals the existence of clear differences between TSCI and NTSCI patients in term of age, gender, extent and level of injury or associated conditions. Among key findings, the data showed that 1) TSCI patients are younger (age of injury) compared with NTSCI individuals; 2) virtually no completely injured patients were found among the group of NTSCI; 3) among men, there were more patients with paraplegia than tetraplegia whereas, among women, the opposite was found (more cases with tetraplegia than paraplegia); 4) most TSCI were cervically or thoracically injured (82\%) whereas NTSCI patients were more evenly distributed at all levels; 5) chronic pain was equally experienced by a majority of patients in both groups (NTSCI and TSCI); and 6) most secondary complications found in TSCI patients were not generally experienced by corresponding numbers of NTSCI individuals. 
Table 4. Type and Completeness Between Male and Female TSCI and NTSCI

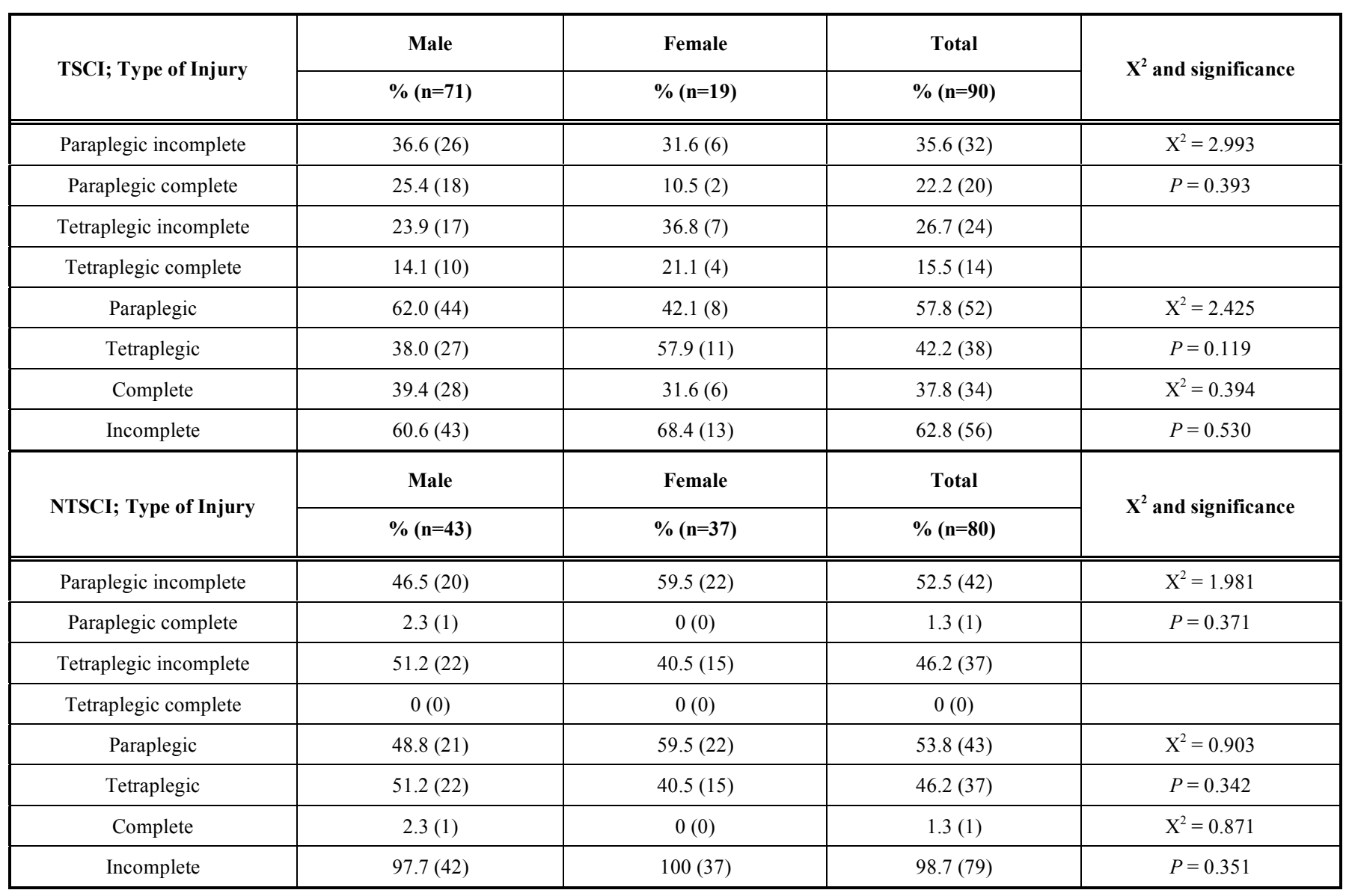

Table 5. Associated Conditions (Secondary Complications) Between TSCI and NTSCI

\begin{tabular}{|c|c|c|c|c|c|}
\hline Associated conditions & Complete $(n=34)$ & Incomplete $(n=56)$ & Total $(n=90)$ & Total $(n=80)$ & $\mathrm{X}^{2}$ and Significance \\
\hline Neurologic bowel & 73.5 & 43.1 & 51.1 & 8.3 & $\mathrm{X}^{2}=34.87$ \\
\hline Urinary tract infection & 32.4 & 11.8 & 26.1 & 2.8 & $\mathrm{P}<0.001$ \\
\hline Pain & 67.6 & 72.5 & 65.2 & 66.7 & $X^{2}=24.25$ \\
\hline Temperature & 5.9 & 19.6 & 13.0 & 8.3 & $\mathrm{P}=0.004$ \\
\hline Spasticity & 58.8 & 47.1 & 48.9 & 29.2 & TSCI Incomp / NTSCI \\
\hline Pressure ulcers & 76.5 & 23.5 & 41.3 & 18.1 & $X^{2}=16.93$ \\
\hline
\end{tabular}

This study was not designed to assess the incidence and prevalence of TSCI and NTSCI patients among the entire population of Trois-Rivieres City, Province of Quebec, or Canada since it is unlikely that this sample (175 patients) allows to reliably assess such values. In fact, there is evidence suggesting that incidence and prevalence numbers are rather difficult to assess appropriately. As an example, for many years, numbers and statistics from the University of Alabama (The National Spinal Cord Injury Statistical Center in the U.S.) were considered as reliable estimates of the incidence and prevalence of TSCI in the U.S. Forty cases per million population was reported as a fair estimate of incidence and 259,0000 Americans currently living with SCI was considered as a fair estimate of prevalence 
(www.spinalcord.uab.edu). Interestingly, an extensive study sponsored by the Christopher and Dana Reeve Foundation has recently reported very different estimates. According to that recent report, the incidence is similar to previous estimates although the prevalence would be significantly higher (e.g., than estimates from the University of Alabama) with $1,275,000 \mathrm{SCI}$ patients ( $0.4 \%$ of the U.S. population). It is unclear if comparable estimates may apply to TroisRivieres or the Province of Quebec. If they do apply, this would correspond to 28,000 patients who could currently be living with TSCI in Quebec. This said, an Ontario (another Canadian province)-based epidemiological study reported 37 to 46 TSCI cases per million population [13]. However, different incidences were reported in other countries such as in Germany (66 cases per million population per year)[14] or France (only 12.7 cases per million population per year)[15], strongly suggesting that incidence and prevalence values (and probably causes) may largely differ from one geographical area to another. On the other hand, studies that have estimated NTSCI incidences are rather rare although numbers as high as 80 cases per million population per year have been reported [16].

Regarding the causes of SCI, data from this study revealed that the etiology of TSCI in the Province of Quebec (Trois-Rivieres City) versus in the U.S. is partially different. The study showed that TSCI patients in Quebec were injured by vehicle accidents $(36.7 \%$ for cars, $8.4 \%$ for motorcycles and $7.4 \%$ for recreational vehicles), falls $(15.8 \%)$, and accidents at work (11.6\%). Comparable percentages (e.g., vehicle accidents) were found in larger Quebec-based (2200 TSCI patients) and Ontario-based studies conducted a few years ago $[13,17]$. In contrast, data from the Christopher and Dana Reeve Foundation-sponsored report indicate that TSCI in the U.S. are caused mainly by accidents at work $(28 \%)$, vehicle accidents (24\%), and falls (9\%)[18]. Among other causes, it is worth noticing that accidents associated with fire arms constitute only $3.1 \%$ of all TSCI patients in this study which is in clear contrast with data from across the boarder where they constitute a leading cause of TSCI in the U.S. [12]. For NTSCI, the main causes in the U.S. are stroke $(29 \%)$ and multiple sclerosis $(17 \%)$ (although discrepancies were reported in specific geographical areas, e.g., Virginia with $53 \%$ of all NTSCI cases caused by stenosis)[19] whereas in Quebec, the present study reports that the mains cause of NTSCI are stenosis-associated myelopathies $(34.5 \%)$.

The gender factor is apparently also different on each side of the North American boarder. Data from this study show that men and women constitute respectively $74.5 \%$ and $25.5 \%$ of TSCI cases whereas, in the U.S., $61 \%$ and $39 \%$ of men and women constitutes the TSCI cases [18]. In contrast, comparable proportions of NTSCI men and women were found in the U.S. (54\% and 46\%) and Quebec $(53.1 \%$ and $46.9 \%)$. One small community-based study conducted in Virginia (U.S.) also reported a 1:1 ratio (NTSCI male to female)[19] which is also supported by data from a large U.K.-based study [20]. Reasons underlying this genderrelated difference among TSCI patients across the U.S.Canada boarder is unclear but may be associated, as described above, with clearly different incidences of vehicle accidents and work-related accidents.
The age-distribution appears to be similar in Quebec (this study) and the U.S. Data from the University of Alabama report that $56 \%$ of the TSCI group are between 16 and 30 years of age (most of which are men) (www.spinalcord. uab.edu) whereas we found in Quebec (Trois-Rivieres) that most TSCI individuals are men between 10 and 30 years of age $(42.9 \%)$.

To our knowledge, proportions of NTSCI versus TSCI within a relatively homogenous population (patients of Trois-Rivieres City and its surroundings who are essentially Caucasian, french-speaking, blue-collar Canadians) have rarely been reported in the literature. This study is among the firsts to report that comparable numbers of TSCI and NTSCI (respectively, 94 and 81 patients in this study) were found within a rather small and homogenous community. Relatively different numbers were reported in small community-based studies regarding NTSCI in India where $60 \%$ of all SCI patients were reported as NTSCI $(64 / 106$ patients) as well as in Turkey and the U.S. where only $32.5 \%$ and $39 \%$ of all SCI patients were NTSCI, respectively $[19,21,22]$. Comparable proportions $(30 \%)$ as those found in the U.S. were found by Guttman in his large U.K.-based study [18]. Interestingly, the Indian study also showed that significantly more NTSCI patients were associated with paraplegia than tetraplegia $(2: 1$ ratio $)$ and $32 \%$ were completely injured which in clear contrast with results from our study reporting a 1:1 ratio (paraplegia : tetraplegia) and virtually no (1\%) completely NTSCI patients (1/81 patients). All and all, it appears that the different numbers (proportions and prevalences) reported in the literature (including those from this study) may be influenced by geographical and thus socio-economical factors.

Very few studies have reported an exhaustive list of secondary complications associated with NTSCI. An Indiabased study with 297 NTSCI patients has reported significant cases of urinary tract infections $(62 \%)$, spasticity $(57 \%)$, chronic pain $(50 \%)$, depression $(38 \%)$, respiratory tract infections $(34 \%)$, constipation (31\%), pressure ulcers $(30 \%)$, contractures (18\%) and sleep disturbance (14\%)[23]. In this study, we also found significant cases of spasticity (29.2\%), chronic pain $(66.7 \%)$ and pressure ulcers $(18.1 \%)$ although percentages are different. Urinary tract infections were rarely found in this small community-based study (only $2.8 \%$ ) which is in clear contrast with the results from the two Indian studies ( $>50 \%$ of all NTSCI cases)[21,23]. However, the extent of secondary complications found here in TSCI patients is also supported by a much larger (2200 TSCI patients) Quebec (province)-based study that reported significantly large percentages of cases with spasticity, urinary tract infections, pressure sores and hypotension [16].

As mentioned earlier, although it is unclear what the prevalence of TSCI and NTSCI is in Quebec, 6,000 patients is often reported to constitute the prevalence of SCI across the entire Province. Thus, data reported here obtained from 175 patients may possibly be representative of the situation in this part of Canada (3\% of all SCI Quebecers). Indeed, several studies published recently reporting comparable sets of data from India or the United States have drawn a number of conclusions based on results from less than $300 \mathrm{SCI}$ medical records (approximately 310 million and 1.18 billion people in the U.S. and India, respectively)[19, 21-23]. 


\section{CONCLUSION}

This study provides evidence that may support the idea that therapeutic treatments either currently used or in development against secondary complications should probably be designed or specifically adapted for subgroups of SCI patients. Along the same line of evidence and based on comparisons with other studies (e.g., in India and U.S.), health professionals (medical doctors, physiotherapists and researchers) may keep in mind that geographical and social related factors probably affect statistics related with incidence, prevalence, and associated chronic conditions.

\section{ACKNOWLEDGEMENTS}

We wish to thank the Interval Rehabilitation Center of Trois-Rivieres for its collaboration and devoted personnel members who have generously provided efforts in retrieving the corresponding medical files and, occasionally, some missing information.

\section{FUNDING}

We wish to thank also Nordic Life Science Pipeline and NeuroSpina Therapeutics that supported this 3 year-study.

\section{REFERENCES}

[1] BaumanWA, Spungen AM, Adkins RH, Kemp BJ. Metabolic and endocrine changes in persons aging with spinal cord injury. Assist Technol 1999;11:88-96.

[2] Bauman WA, Spungen AM . Metabolic changes in persons after spinal cord injury. Phys Med Rehabil Clin N Am 2000;11:109-40.

[3] Cruse JM, Lewis RE, Dilioglou S, Roe DL, Wallace WF, Chen RS. Review of immune function, healing of pressure ulcers, and nutritional status in patients with spinal cord injury. J Spinal Cord Med 2000;23:129-35.

[4] Giangregorio LM, McCartney N. Bone loss and muscle atrophy in spinal cord injury: epidemiology, facture prediction, and rehabilitation strategies. J Spinal Cord Med 2006;29:489-500.

[5] McKinley WO, Tewksbury MA, Godbout CJ. Comparison of medical complications following nontraumatic and traumatic spinal cord injury. J Spinal Cord Med 2002;25:88-93.

[6] Ho CH, Wuermer LA, Priebe MM, Chiodo AE, Scelza WM, Kirshblum SC. Spinal cord injury medicine. 1. Epidemiology and classification. Arch Phys Med Rehabil 2007;88:S49-54.
[7] McColl MA, Charlifue S, Glass C, Savic G, Meehan M. International differences in ageing and spinal cord injury. Spinal Cord 2002;40:128-36.

[8] Jacob KS, Zachariah K, Bhattacharji S. Depression in individuals with spinal cord injury: methodological issues. Paraplegia 1995;33:377-80.

[9] Lawton G, Lundgren-Nilsson A, Biering-Sorensen F, et al. Crosscultural validity of FIM in spinal cord injury. Spinal Cord 2006; 44:746-52.

[10] Rouleau P, Guertin PA: Traumatic and non-traumatic spinal cordinjured patients in Quebec, Canada. Part 2: biochemical profile. Spinal Cord 2010;48:819-24.

[11] Rouleau P, Guertin PA: Traumatic and non-traumatic spinal cordinjured patients in Quebec, Canada. Part 3: Pharmacological profile. Spinal Cord 2010; (Epub ahead of print).

[12] Kroll T. Rehabilitative needs of individuals with spinal cord injury resulting from gun violence: the perspective of nursing and rehabilitation professionals. Appl Nurs Res 2008; 21: 45-9.

[13] Pickett W, Simpson K, Walker J, Brison RJ. Traumatic spinal cord injury in Ontario, Canada. J Trauma 2003;55:1070-76.

[14] Koning W, Frowein RA. Incidence of spinal cord injury in the Federal Republic of Germany. Neurosurg Rev 1989;12:562-66.

[15] Minaire P, Castanier M, Girard R, Berard E, Deidier C, Bourret J. Epidemiology of spinal cord injury in the Rhone-Alps Region. France 1970-1975. Paraplegia 1978;16:76-87.

[16] Kurtzke JF. Epidemiology of spinal cord injury. Exp Neurol 1975;48:163-236.

[17] Noreau L, Proulx P, Gagnon L, Drolet M, Laramée MT. Secondary impairments after spinal cord injury. A population-based study. Am J Phys Med Rehabil 2000;79:526-35.

[18] Andresen E, Barrington W, Cahill A, et al. One degree of separation. Paralysis and spinal cord injury in the United States. Christopher and Dana Reeve Foundation, 2009. Available from: http://www.christopherreeve.org

[19] McKinley WO, Seel RT, Hardman JT . Nontraumatic spinal cord injury: incidence, epidemiology, and functional outcome. Arch Phys Med Rehabil 1999;80:619-23.

[20] Guttman L. Spinal cord injuries. Comprehensive management and research. Oxford: Blackwell 1973.

[21] Gupta A, Taly AB, Srivstava A, Murali T . Non-traumatic spinal cord lesions: epidemiology, complications, neurological and functional outcome of rehabilitation. Spinal Cord 2009;47:307-11.

[22] Ones K, Yilmaz E, Beydogan A, Gultekin O, Caglar N. Comparison of functional results in non-traumatic and traumatic spinal cord injury. Disabil Rehabil 2007;29:1185-91.

[23] Nair KP, Taly AB, Maheshwarappa BM, Kumar J, Murali T, Rao S. Nontraumatic spinal cord lesions: a prospective study of medical complications during in-patient rehabilitation. Spinal Cord 2005;43:558-64. 